\title{
ENTRE A COMUNIDADE E A UNIVERSIDADE: AUGUSTO ÓPẼ DA SILVA E A LUTA DOS POVOS INDÍGENAS PELO ACESSO AO ENSINO SUPERIOR ${ }^{1}$
}

\author{
ALESSANDRO BARBOSA LOPES ${ }^{2}$ \\ UFPel
}

ROBERTA DE SOUZA CADAVAL ${ }^{3}$

UFPel

Este texto tem como objetivo apresentar a transcrição da fala de Augusto Ópẽ da Silva exposta no Fórum Nacional de Educação Superior Indígena: Institucionalização e Implementação de Ações Afirmativas na FURG, no ano de 2012, na Universidade Federal do Rio Grande (FURG), bem como a importância de Augusto no processo de ingresso de estudantes indígenas nesta instituição.

Este importante evento transcorreu durante os dias 17 e 18 de maio de 2012 e foi registrado em vídeo pelo Laboratório Audiovisual de Pesquisa em Educação Ambiental (LAPEA), vinculado ao Programa de Pós Graduação em Educação Ambiental da FURG.

Nesta ocasião, acadêmicos da universidade, professores da rede pública de ensino e de universidades da região sul, técnicos administrativos, indígenas, lideranças e membros da comunidade rio- grandina, se reuniram para uma reflexão conjunta sobre o acesso e permanência de indígenas na nesta instituição de ensino.

O processo de ingresso de estudantes indígenas nesta instituição se deu no ano de 2009, a partir do encontro de um professor do curso

\footnotetext{
${ }^{1}$ Agradecemos ao Prof. Dr. Rogério Réus Gonçalves da Rosa pelo convite em prestar esta homenagem ao Augusto Ópẽ da Silva, e ao Prof. Dr. Alfredo Martin Gentini por ceder-nos o material audiovisual produzido pelo LAPEA para que pudéssemos efetuar a transcrição da fala de Augusto.

${ }^{2}$ Mestrando do Programa de Pós-Graduação em Antropologia da Universidade Federal de Pelotas. Email: alessandro.b.lopes@ @otmail.com .

${ }^{3}$ Mestre em Antropologia pelo Programa de Pós-Graduação em Antropologia da Universidade Federal de Pelotas. E-mail: robertakdaval@hotmail.com .
}

Espaço Ameríndio, Porto Alegre, v. 8, n. 2, p. 386-394, jul./dez. 2014. 
de Psicologia da FURG, Prof. Dr. Alfredo Martin, com o Kaingang Augusto Ópẽ da Silva. De acordo com o professor citado, em uma de suas caminhadas à Avenida Rio Grande (no Balneário Cassino, na cidade de Rio Grande - RS), um dos locais onde os Kaingang vendem seus artesanatos durante o verão (de janeiro a março, aproximadamente), Martin parou para conversar com tais indígenas. Desse diálogo, houve o interesse, de ambas as partes, para que os indígenas tivessem um espaço para dialogar com os alunos na disciplina de Psicologia Transcultural - recém-criada naquele momento. Assim, o Cacique Roberto dos Santos ofereceu a primeira aula, explicando aos alunos do $2^{\circ}$ ano de Psicologia a sua experiência indígena, suas mitologias e cosmovisões, suas problemáticas da terra, da história kaingang, etc. Finalizou convidando os alunos para visitar a aldeia de Iraí.

Essa visita, conforme a memória do Professor Alfredo, foi feita no mês seguinte com toda a turma. Ali passaram três dias compartilhando a vida dos indígenas, fazendo entrevistas, escutando as crianças, os velhos, os professores, os profissionais do posto de saúde e, sobretudo, o Augusto Ópẽ da Silva, que explicou várias histórias de etnia e dos processos de cura tradicionais.

Finalizando o encontro, o Cacique Roberto solicitou a abertura da Universidade para os jovens kaingang. Sendo assim, o Professor Alfredo buscou formas de concretizar esses interesses, através da Pró-Reitoria de Assuntos Estudantis (PRAE) e da Pró-Reitoria de Graduação (PROGRAD) da FURG. Dessa forma, foi criada, em 2009, a Comissão de Acesso e Permanência do estudante indígena na FURG através do Programa de Ações Inclusivas (PROAI). O principal objetivo da Comissão é democratizar o acesso ao ensino superior, valorizando a diversidade cultural e étnica.

Transcorridos três anos após este processo, este evento era também um momento onde a FURG apresentava e avaliava o seu programa de ações afirmativas que estava em curso, além de pôr em diálogo e evidência os indígenas universitários diante de toda comunidade acadêmica. Um momento importante, de negociações e ajustes nas ações da universidade para com os povos indígenas. Augusto Ópẽ da Silva estava lá, na condição de influente e respeitado 
líder indígena, circulava por diversas regiões, sempre requisitado a falar sobre os direitos dos povos indígenas, terras, saúde, educação.

Nesta ocasião, Augusto foi convidado a falar sobre a educação formal na óptica dos Kaingang. Suas palavras carregavam o peso da memória, das vivências, eram um sopro de sabedoria nos ouvidos daqueles com quem dividia o mesmo espaço. Ao lado de Davi Kopenawa Yanomami e Maurício Yekuana, Augusto trazia elementos da história indígena no Rio Grande do Sul em paralelo a uma visão crítica sobre o acesso e permanência de indígenas no estado. Uma verdadeira e preciosa aula que temos o prazer de partilhar a seguir.

Muitos índios fugiram desse modelo de educação. A minha irmã mais velha, que tá com oitenta anos, foi vítima desse processo, desse projeto genocida que 0 governo implantou dentro das terras indígenas. Uma vez que a minha irmã foi na aula, eu nem tinha nascido na época, mas o relato dela, o relato do meu pai... isso ficou gravado na minha memória. Uma vez que a minha irmã foi na aula, ela falou uma palavra indígena dentro da sala de aula e as professoras e a direção da escola bateu nela. Ela chegou em casa chorando né, com o caderninho dela. Meu pai perguntou pra ela, minha mãe perguntou: $O$ quê que aconteceu, minha filha? Os professores me surraram por eu ter falado minha língua. Aí que que aconteceu, ferveu o sangue do velho né, levantou e foi lá na escola, falar com a direção e brigou lá com a direção. Disse pra direção: $A$ minha filha não é obrigada a aprender a língua de vocês. Ela não é obrigada a aprender a língua de vocês. Ela tem outras atividades dela. Ela tem outra cultura. Eu não vou deixar a minha filha vim mais nessa escola aí. E que não faz parte da nossa cultura. Meu pai voltou, chegou em casa e disse pra minha mãe: Pega a menina e pega a mochila e vamos sair pra longe desses brancos que tão explorando nós [que era o Serviço de Proteção aos Índios - SPI].

No tempo do SPI muitos índios sofreram, até mesmo foram escravos. Trouxeram projeto chamado panelão, que era pra fazer comida para os índios escravos. Pra nós, nossos pais, nossos avôs, que eram escravos. Até as mulher foram escravizadas. Fizeram nossos pais, nossas mães aprender a plantar o soja, que não faz parte da nossa cultura. Eles fizeram que nós virasse o sistema capitalista, capitalismo, monocultura, e trouxeram vários tipos de sementes pra dentro das terras indígenas. 
Meu pai e a minha mãe fugiram com a minha irmã, foram morar bem longe do escritório do SPI, lá a minha irmã teve outras atividades pra ela fazer. Aprender a trabalhar as atividade dela dentro da cultura dela. Então durante esse período de tempo ainda o governo não organizou uma educação diferenciada. Não construiu uma casa específico para nós, tanto para o Guarani, tanto para o Xokleng, tanto para o Kaingang. Não enxergou essas diferenças que existem. Ele civilizou de uma maneira não indígena. Nós, índios, entendemos a palavra civilização, significa as nossas diferenças. As nossas diferenças como povo, as nossas organização social. Só que o governo não viu essas diferença de civilização. Que que ele fez? Ele juntou negro, juntou alemão, juntou italiano, juntou polonês, juntou japonês, juntou o índio, botou tudo no mesmo saco e fez uma civilização só. Tudo pelo contrário ele fez.

Hoje nossa luta é pra ter educação diferenciada. Hoje a nossa luta é pra cidadania. Que dentro do nosso país o que tá faltando é o respeito entre nós, entre as diferenças, tanto não índio como índio, como negro. Falta o respeito entre as nossas diferenças. Isso que tá faltando nesse país.

Lutamos muito contra essas escolas, para criar-se educação diferenciada. Nós era considerado de menor, na época do SPI, a até uma altura a Funai também, considerado de menor, e só eles podiam fazer pra nós tipo de educação que nós queria. Só eles podiam fazer qual tipo de saúde que eles queriam, proibiam nossos pajés a usar as nossas ervas medicinais, prendiam nossos kujà, né, quando tá fazendo ritual pra uma comunidade, pra fazer as curas. Nossos kujà era presos pelo SPI. Então tudo isso nós sofremos na história e sempre fomos considerado de menor até os anos oitenta e oito.

São várias constituições federais que foi criado na história do Brasil. Sete foi criado e nenhuma dessas sete garantiu nenhum direito em nome das comunidades indígenas. A última constituição federal criada em oitenta e oito - são oito que foi criado - nós se organizamos com esses duzentos e vinte povos que tem no Brasil, que são sobreviventes do massacre físico, cultural, feito pelos colonizadores. Se organizamos nessa época, fomo pra Brasília quando a ultima constituição tava sendo votada no congresso nacional. Fomos de burduna, fomos de arco e flecha, fomos de lança, fomos pintados, fomos de cocar, dando nossos gritos de luta, quando os deputados tavam votando na última Constituição. Nesta época, o 
governo, os políticos votaram pela primeira vez na história alguns direitos importantes pra nós. A garantia das demarcações das nossas terras, a garantia de ter uma política diferenciada na área da educação, na área da saúde, mas o governo não respeitou ainda. O governo não botou em prática ainda, continua fazendo a casa mal-construída. Todo que nos alimenta é nossa cultura, todo que nos alimenta é a natureza. Nós temos muito amor pela natureza. Todos os povos indígenas que existem nesse país, nós temos o mesmo pensamento. Nós temo um sonho. Nós temo um sonho assim que um dia nós vamo conseguir um mundo melhor. Outro mundo é possível, se nós se organizar. Mas enquanto que não tiver respeito entre as diferenças não é possível nós construir um mundo melhor. Respeitar os nossos direitos.

Hoje nós tamos lutando para que crie uma universidade ligada a nossa cultura. Uma universidade diferente. Por isso é bom nós estarmos aqui, garanto que tem várias pessoas que estão aqui, com vários cursos. Nós fomos sempre excluídos pela sociedade, nós sempre fomos excluídos pelas universidades, que os acadêmicos não indígenas iam fazer pesquisas lá fora do país, enquanto que nós índios brasileiros estamos aqui convivendo, então na história foi uma exclusão muito forte e ainda tá tendo. Em oitenta a gente começou a olhar, na época que eu fui liderança, fui cacique em oitenta, na minha terra lá de Iraí, eu comecei a me preocupar pelo espaço, de terras, pelas demarcações de terras e pelos jovens. Eu era bem jovem na época. Comecei a luta pelas demarcações de terras porque o governo tinha roubado nossas terras em sessenta e dois com o projeto de reforma agrária. Não somos contra a reforma agrária, mas o governo não podia ter feito em cima das nossas terras. E quem sofre com isso é os dois pequenos grupos, $o$ pequeno agricultor $e$ as comunidades indígenas.

Retomamos nossas terras em 92, quando nós demarcamos a terra indígena de Iraí. Retomemo a luta, nesta época, todas as comunidades se despertaram e voltaram a retomar seus antigos territórios. Aí que que os brancos falam de nós? Falam que nós não precisamos de terra, semo preguiçosos, bêbados, falam que nós semos invasores, enquanto que nós tava ocupando nossos antigos territórios. Nós índios nunca invadimos, não sei por que que os brancos tem essa palavra de dizer pra nós que nós somos invasores. Isso tá muito errado. Nós temo é que entender onde é que tá a falha, como que tá hoje. Nós temo que aprender a conviver. 
Nós lutamos pela universidade no ano de 1980, quando eu comecei a me preocupar. Eu pensei que os índios também tem que ter uma formação que nem os brancos tem, que nem o não indio tem. Lutei pra abrir uma porta da universidade que é Unijuí [Universidade Regional do Noroeste do Estado do Rio Grande do Sul]. $\mathrm{Na}$ época poucas comunidades tinha, poucas pessoas tinha formado para fazer vestibular. Pessoal de Guarita conseguiram entrar porque eles tinham mais jovem que tavam formado. Graças a eles que foram abrindo as portas. Só que nós não discutimos, nós líderes não discutimos porque era uma coisa nova pra nós. Era uma coisa que não faz parte da nossa cultura. Hoje tá sendo muito discutido. Eu já tinha parado até pra discutir curso superior indígena. Eu retomei há pouco tempo, quando a gente organizou movimentos, quer dizer, com a vinda de famílias indígenas pra cá pra mostrar e comercializar os artesanatos, pra divulgar a cultura. Porque muitas vezes as pessoas acham que 0 balaio que tá aqui, o arco e flecha que tá aqui, acha que é simplesmente qualquer artesanato, mas pra nós ele é muito importante. É um símbolo de resistência de mais de 500 anos que esse balaio tem. 0 arco e flecha são 512 anos de resistência, que nossas mulheres utilizavam o balaio pra ir coletar frutas na floresta, o alimento. Os arco e flecha que nós usava pra pescar, pra caçar. Então são símbolos de resistência.

Na primeira vez que nós viemos aqui, não me lembro que ano, nós fomos $100 \%$ discriminados pela sociedade. Resistimos graças lideranças também que vieram pra cá e resistiram. Não é o direito e direito e direito. Fomos no Ministério Público várias vezes. Mas a discriminação foi muito forte aqui na cidade do Rio Grande, na praia do Cassino. Então a resistência fez acontecer as coisas.

A minha aldeia é um povo que luta, é um povo que batalha, é um povo que tem cultura, fomos resistindo até os não índios entender nós. Fomos conseguindo os espaços com nossa luta. Conseguimos discutir a universidade. Conseguimos aprofundar a discussão quando os acadêmicos não índios foram na minha aldeia, ficaram mais de uma semana lá. Tá aí o Professor Alfredo, que levou uma turma de estudantes na minha aldeia lá.

É isso aí que tem que acontecer.

Aprender a conviver. Aprender a conhecer mais de perto a realidade do nosso povo. E foi muito importante pra mim, professor Alfredo. Foi muito importante pra todos nós, nesta época eu aprofundei muito a discussão com o professor Alfredo. Já vim várias vezes aqui 
defender. Muitas vezes as universidades querem fazer do jeito que acham que tem que ser. Muitas vezes eles acham que nós tem que entrar nas cota do governo. Mas nós semo diferente. Essa briga eu comprei muito aqui na universidade e lá de Santa Maria. Se não tem um programa diferenciado na universidade, a universidade tem toda a obrigação de criar. Ali a lei fala, qualquer governo no Município, no Estado, na União, se não tem programa em relação a comunidade indígena, tem que ser criado. Qualquer município onde o índio faz presença e não tem programa com os índios, o município tem que criar. Assim diz a lei. E nós tamo batalhando muito em cima da nossa lei, que nós conquistamos com muito sofrimento na Constituição de 88.

Conseguimos avançar... Atendimento diferenciado na UFRGS [Universidade Federal do Rio Grande do Sul], em Santa Maria e aqui na FURG. Mas não foi a universidade que botou o pessoal, essa é a diferença. Lutamos, as lideranças lutaram pra que se tenha atendimento diferenciada. Santa Maria a gente lutou muito para a universidade criar atendimento diferenciado para a nossa juventude. Não é pegar o índio, abrir a porta da universidade e jogar o índio pra dentro e dizer "te vira, índio". Não! Vamos pensar juntos. Vamos discutir juntos. Vamos construir uma universidade de verdade, com as nações que existem aqui nesse país. Por enquanto, no nosso ponto de vista, não existe universidade na prática. Porque existem diferenças. Até em nós, nos índios, tem. Até o Guarani, que é diferente na língua, só que os direitos é os mesmos. Guarani tem um ritual diferente. Um trabalho diferente. Só que a universidade não tá ainda discutindo isso. Mas tá no momento de nós discutir.

Não foi por acaso que Santa Maria hoje tem vaga. Foi uma luta. Não é por acaso que foi criado atendimento diferenciado. Ela é diferenciada. Ela não é específico ainda. Quando se fala de específico, é uma palavra muito forte. Específico vai ficar quando todos nós entendermos o que que é cultura indígena e cada povo. Muitos hoje não falam a língua, é por isso que não é específico ainda, mas o momento vai chegar. Nós não queremos se discriminar um ao outro. Porque cada um que não fala a língua hoje tem história de sofrimento. Tem história de sofrimento, tem história de discriminação, tem história de preconceito. Principalmente quando o governo fez esses projeto genocida, quando o índios fugiam das suas aldeia e foram morar nas periferias das cidades, principalmente na reforma agrária muitos índios saíram da sua aldeia e 
foram morar nas periferias da cidade, em 62 isso aconteceu. Muitos índios foram morar na beira da estrada, muitos índios foram morar em baixo de ponte, muitos líderes foram mortos, muitas crianças morreram nessa época, de pneumonia e de fome, porque os brancos já tinham tomado suas terras. Então não é por acaso que tem índio que não fala a língua, não são culpado, então por isso que nós tamo estudando muito até chegar o específico, sem discriminar os índios nossos parente que não falam. Ele é diferenciada, nós queremo que ela seja criada diferenciada. Nós queremos que a universidade visite nossas aldeias. Nós queremos que a universidade faz a prática, discute, acompanhamento. Que a nossa cultura tem que continuar viva. Tem o meu filho que tá fazendo Letras e minha filha que se formou em Pedagogia, cem por cento ela fala a língua materna, domina bem as duas línguas. Meu filho dizia: "Pai, eu vou me doutorar em Letras, mas eu não vou chegar cem por cento igual o branco, porque minha cultura não fecha com isso".

$\mathrm{E}$ onde tiver um ou dois índios, vão tar falando a cultura, então a juventude tá se preocupando. Hoje nós temo um pé na luta pra conseguir espaço nas universidade mas com um pé lá, lá na base, um pé... um pé pra reivindicar as política pública, mas também com um pé na cultura. Se nós botar os dois pé só dentro da universidade nós vamo acaba se terminando. O que nós se preocupamos muito é que hoje existe muito pessoas gananciosas, nós semo diferente, nós semo povo de igualdade. Não existe índio superior e índio inferior. É por causa dessa ganância dos governador, dos estado, de todos os governo, a ganância, por isso tá existindo muita pobreza, uns quer ter mais que o outro. Tá existindo pobreza por causa disso. Se o governo souber distribuir bem as terra, tem terra pra todos nós, tanto pro branco, tanto pro índio, tanto pro negro, só que a ganância tá muito forte, por isso que existe pobreza nesse país e pra nós construir um país de igualdade tem que existir respeito e igualdade. Eu vou parando por aqui e talvez vai ter questionamento e a gente tá disposto a responder. Obrigado.

\section{Referências Videográficas}

Espaço Ameríndio, Porto Alegre, v. 8, n. 2, p. 386-394, jul./dez. 2014. 
HOMENAGEM A AUGUSTO ÓPẼ DA SILVA

Fórum indígena 2012. Vídeo realizado pelo Laboratório Audiovisual de Pesquisa em Educação Ambiental - LAPEA/PPGEA/FURG, 2012.

Espaço Ameríndio, Porto Alegre, v. 8, n. 2, p. 386-394, jul./dez. 2014. 